\title{
Role of Corneal Cross-linking and Phakic Intraocular Lens Implantation in Progressive Keratoconus
}

\author{
1Jose L Güell, ${ }^{2}$ Merce Morral, ${ }^{3}$ Miriam Barbany, ${ }^{4}$ Oscar Gris, ${ }^{5}$ Daniel Elies, ${ }^{6}$ Felicidad Manero
}

\begin{abstract}
Background: The two most important goals of management of keratoconus and other corneal ectatic diseases are halting disease progression and visual rehabilitation. Several treatment strategies to skip corneal transplantation have been developed but controversies of the best treatment option for a given patient still exist. The combination of CXL and PIOL implantation has been proposed for visual rehabilitation in patients with progressive keratoconus.
\end{abstract}

Aim: To review the published clinical evidence on the combination of corneal cross-linking (CXL) and phakic intraocular lenses (PIOLs) in patients with keratoconus.

Results: No randomized controlled trials and only four retrospective case series were identified. The progression of keratoconus was stopped in all eyes and satisfactory visual rehabilitation was achieved both in terms of uncorrected and corrected distance visual acuity (CDVA) and predictability of refractive correction.

Conclusion: Corneal cross-linking combined with PIOL implantation is a valid therapeutic approach for progressive keratoconus with moderate-to-high refractive errors, regular or mildly irregular astigmatism, and good CDVA, especially in the face of significant anisometropia.

Clinical significance: The combination of CXL and PIOL implantation is a valid therapeutic approach for visual rehabilitation of progressive keratoconus. Although longer-term follow-up clinical data from prospective randomized clinical trials (RCTs) are needed, clinical outcomes are excellent and equivalent to nonkeratoconic eyes up to 3 years after surgery.

Keywords: Astigmatism, Corneal Crosslinking, Ectasia, Irregular astigmatism, Keratoconus, Phakic Intraocular Lenses, Progression.

\footnotetext{
${ }^{1}$ Director, ${ }^{2-6}$ Consultant

${ }^{1}$ Department of Cornea and Refractive Surgery Unit, Instituto de Microcirugia Ocular, Barcelona, Spain; Institut de Microcirugia Ocular, Barcelona, Spain; European School for Advanced Studies in Ophthalmology, Lugano, Switzerland; Department of Ophthalmology, Universitat Autonoma de Barcelona, Barcelona Spain

${ }^{2-6}$ Department of Cornea and Refractive Surgery, Institut de Microcirugia Ocular, Autonoma University of Barcelona Barcelona, Spain

Corresponding Author: Merce Morral, Consultant, Department of Cornea and Refractive Surgery, Institut de Microcirugia Ocular, Autonoma University of Barcelona Barcelona, Spain e-mail: merce.morral@gmail.com
}

How to cite this article: Güell JL, Morral M, Barbany M, Gris O, Elies D, Manero F. Role of Corneal Cross-linking and Phakic Intraocular Lens Implantation in Progressive Keratoconus. Int J Kerat Ect Cor Dis 2018;7(1):26-30.

Source of support: Nil

Conflict of interest: None

\section{BACKGROUND}

Diagnosis and management of keratoconus and other corneal ectatic diseases have significantly evolved during the past two decades. Topo-tomography has allowed the diagnosis of these diseases at a much earlier stage, which permits more conservative treatment approaches. Corneal transplantation is reserved for those cases where functional vision cannot be obtained with the nonsurgical and surgical alternatives currently available. ${ }^{1-4}$

A wide variety of treatment strategies, which include glasses, contact lenses, CXL, intracorneal ring segments, and/or PIOLs, have been developed in parallel with innovations in refractive surgery. Still, many controversies exist in terms of the best treatment option for any given patient. In 2015, a global project was developed that resulted in definitions, statements, and recommendations for the diagnosis and management of keratoconus and other ectatic diseases, which also provided an insight into the current worldwide treatment of these conditions. ${ }^{5}$ The two most important goals of management are halting disease progression and visual rehabilitation. Different case scenarios were discussed based on patient's age, keratoconus progression, and the possibility of satisfactory vision with glasses or contact lenses.

Visual rehabilitation of the ectasia usually requires a step-wise approach that involves: (1st) To stabilize the disease if progression is observed, (2nd) correct or compensate irregular astigmatism, and (3rd) correct regular astigmatism and spherical refractive error. As a rule, anyone with progressive ectasia should undergo CXL no matter what age or level of vision (assuming the eye was an appropriate candidate).$^{5}$ Once stabilized, PIOLs constitute an excellent alternative in patients with stable mild-to-moderate corneal ectasia and with moderate-tohigh refractive errors who are contact lens intolerant and who fulfill the criteria for their implantation. This article focuses on the role of CXL associated with PIOLs in our clinical practice. 


\section{RESULTS}

\section{Corneal Cross-linking and Keratoconus}

Corneal cross-linking is the only technique that has a proven effect on stopping the progression of keratoconus. Progression of keratoconus is diagnosed when one or more of the following are present: Refractive shift (especially changes in cylinder magnitude and/or axis) of more than $0.75 \mathrm{D}$; increase on corneal SimK greater than $1 \mathrm{D}$; and/or decrease of central pachymetry greater than $25 \mu \mathrm{m}$ demonstrated in at least two consecutive examinations 6 to 12 months apart.

Recently, the U.S. multicenter RCT proved that CXL was effective in improving the maximum keratometry value, CDVA, and uncorrected distance visual acuity (UDVA) in eyes with progressive keratoconus 1 year after treatment, with an excellent safety profile. ${ }^{6}$ An RCT comparing transepithelial CXL using iontophoresis (T-ionto CL) and standard CXL with the Dresden protocol showed that significant visual and refractive improvements were found 12 months after T-ionto CL, but the average improvement in corneal topography readings was slightly lower than the Dresden protocol in the same period. ${ }^{7}$ Choi et al ${ }^{8}$ compared the accelerated CXL with the Dresden protocol. Despite a higher ultraviolet (UV) dose $(6.6 \mathrm{~J} / \mathrm{cm})$, accelerated CXL with higher UV intensity and reduced irradiation time showed a smaller topographic flattening effect than did the conventional Dresden protocol in primary keratoconus with documented progression.

Our standard CXL procedure is as follows:

Collagen cross-linking of the cornea was performed in the operating room under sterile conditions, and topical anesthesia with proparacaine $0.5 \%$ ( 1 drop every 5 minutes for 3 doses immediately before surgery). The central 7 to $8 \mathrm{~mm}$ diameter of the corneal epithelium was cautiously removed using a hockey blade. As a photosensitive, riboflavin $0.1 \%$ solution (10 $\mathrm{mg}$ riboflavin5-phosphate in $10 \mathrm{~mL}$ dextran-T-500 20\% solution) was instilled every 5 for 20 minutes until the corneal stroma was completely soaked, and then every 5 minutes during the 30-minute irradiation with UV-A light. The UV-A irradiation was performed using the UV-light-emitting diode $(370 \mathrm{~nm}$ ) from the LightLink-CXLTM (LightMed USA, San Clemente, CA) at a working distance of $5 \mathrm{~cm}$, with irradiance density between 2.7 and $3.3 \mathrm{~mW} / \mathrm{cm}^{2}$ and dose $5.4 \mathrm{~J} / \mathrm{cm}^{2}$ using the standard protocol. After the treatment, the ocular surface was washed out with profuse irrigation with balanced salt solution (BSS ${ }^{\circledR}$ Alcon Cusi) and two drops of tobramycin $3 \mathrm{mg} /$ $\mathrm{mL}$ and dexamethasone $1 \mathrm{mg} / \mathrm{mL}$ (Tobradex; Alcon Cusi S.A., Barcelona, Spain) were instilled, followed by the placement of a bandage soft contact lens (BSCL).
Postoperatively all patients were prescribed oral metamizole (Nolotil ${ }^{\circledR}$, Boehringer Ingelheim, Spain) if required, with a maximum dose of $1 \mathrm{gm}$ QID. All patients underwent topical treatment with ofloxacine (Exocin; Allergan S.A., Madrid, Spain) 1 drop QID, and preservative-free artificial tears hourly. Once complete re-epithelialization was achieved (4-7 days after surgery), the BSCL was removed, and topical ofloxacine was stopped. This was followed by fluorometholone 0.1\% (FML FORTE; Allergan S.A., Madrid, Spain) 1 drop TID for 3 weeks, and then slowly tapered down during a minimum of 6 weeks, depending on the cornea's inflammatory reaction.

\section{Corneal Cross-linking combined with PIOLs}

In our institute (Instituto de Microcirugía Ocular, Barcelona, Spain), the combination of CXL and PIOL implantation is indicated in those patients with documented progressive keratoconus, who are contact lenses intolerant, or who seek refractive surgery to correct moderate-to-high refractive errors, including myopia, hyperopia, and/or astigmatism. Patients with significant irregular astigmatism or CDVA $<20 / 50$ are generally excluded. Other standard inclusion criteria are clear cornea, corneal thinnest point $>400 \mu \mathrm{m}$ measured by ultrasound pachymetry, central anterior-chamber depth $>3.0 \mathrm{~mm}$, measured from the corneal endothelium to the anterior surface of the crystalline lens, central endothelial cell counts $>2300$ cells $/ \mathrm{mm}^{2}$, normal iris morphology and pupil function, mesopic pupil size $<4.5 \mathrm{~mm}$, and absence of other ocular pathology or systemic disease that may alter the healing response. In cases with corneal thinnest point $<400 \mu \mathrm{m}$, we may consider to use hypoosmolar riboflavin depending on the degree of the ectatic disease.

Indications, contraindications, and surgical technique of PIOLs in patients with keratoconus have been previously reported and are essentially the same as in nonkeratoconic eyes. ${ }^{2,9}$ All patients are warned of the benefits and potential risks of the surgery, the potential progression of keratoconus and the potential change in refractive error despite CXL.

There is still no consensus on the appropriate interval between CXL and PIOLs implantation. ${ }^{10-12}$ In our experience, after a minimum of 3 months following CXL, PIOL is considered once both manifest refraction and tomography scans are stable between two different time-points separated at least 2 months. However, there is a variability in the response to CXL that depends, among others, on the degree of ectasia, patient's age, and biomechanical properties of the cornea. Thus, the minimum interval between CXL and PIOL implantation should be individually determined. ${ }^{13,14}$ Other authors 

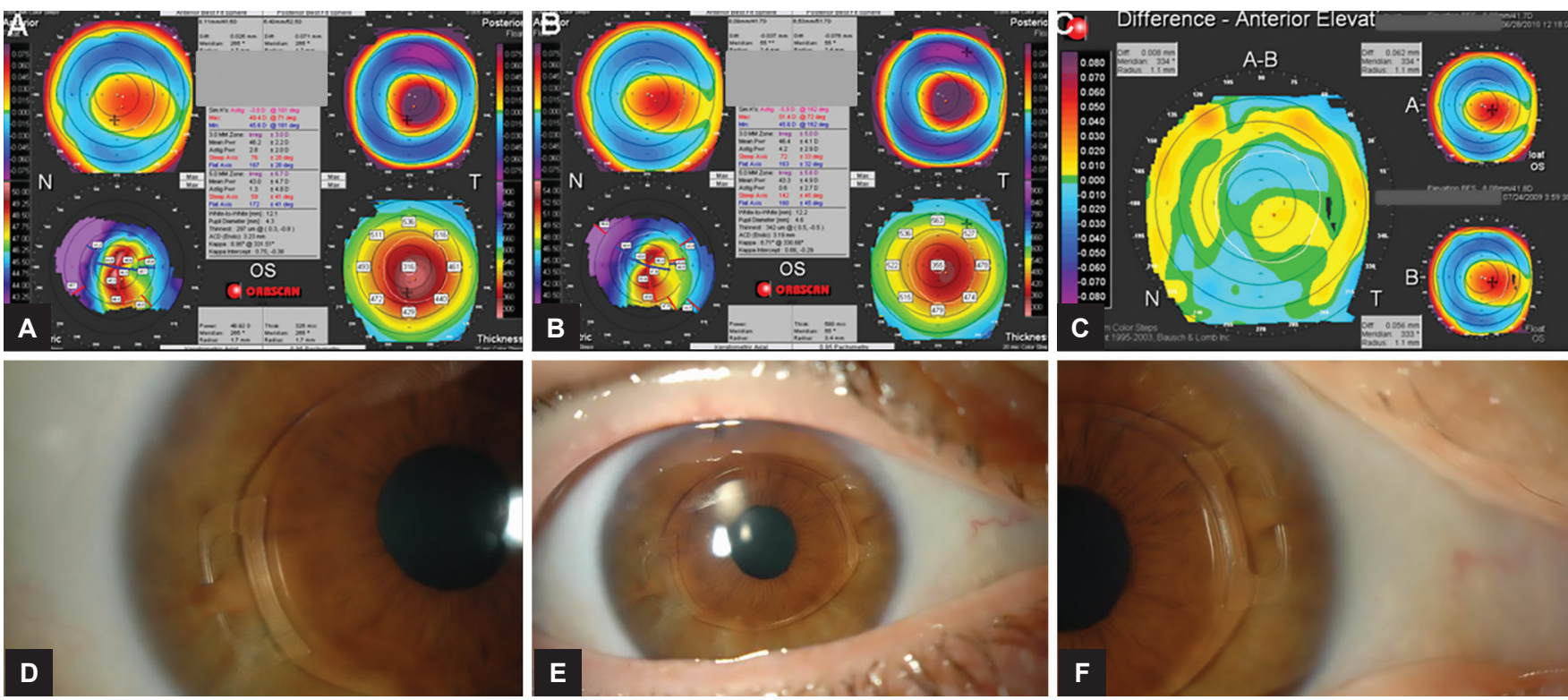

Figs 1A to F: Orbscan topographies of a patient with progressive keratoconus. (A) Before CXL; (B) 5 months after CXL; (C) anterior elevation difference map before and after CXL. Stability of the keratoconus can be observed. (D-F) Toric Artiflex (Ophtec, Groningen, The Netherlands) PIOL properly implanted and centered in a patient previously operated of CXL. High magnification showing the appropriate amount of iris tissue grasped with the iris claw

have suggested to wait at least 6 months. ${ }^{10}$ Most importantly, when a temporary reduction of CDVA after CXL is observed, the implantation surgery should be delayed until CDVA has reached at least preoperative values. Figure 1 shows slit-lamp photograph and topographies of one of our treated patients.

\section{DISCUSSION}

\section{Clinical Results of the combination of CXL and PIOL Implantation in Patients with Keratoconus}

Outcomes of PIOL implantation in nonprogressive, keratoconic eyes are comparable to nonkeratoconic eyes in terms of efficacy, safety, and stability of refractive results., ${ }^{915-19}$ Both implantable collamer lenses (Visian ICL, STAAR Surgical Monrovia, CA) and the iris-claw PIOL (Artisan-flex, Ophtec, Groningen, the Netherlands) have been proposed as a valid alternative for the correction of the stable myopic astigmatism in patients with keratoconus. ${ }^{2,17-21}$

Published clinical experience of the results of the combination of CXL and PIOL implantation in patients with

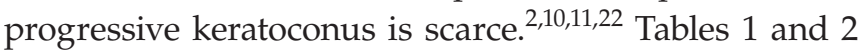
summarize the main outcomes of these studies. Spherical equivalent, cylinder, and minimum, maximum, and mean keratometry remain stable up to 4 years after CXL + PIOL implantation, which demonstrates the efficacy of CXL in stopping the progression of the cone. Predicatibility of refractive correction and safety in terms of visual acuity and the corneal endothelium is equivalent to nonkeratoconic eyes. In our study, we did not find any significant loss of endothelial cell density up to 3 years after surgery, which suggests that the combination of CXL and toric Artiflex does not result in any additional loss. ${ }^{2,915,23}$ Regardless, ECC should be monitored at yearly intervals in all patients, as long-term studies have reported a significant decrease in ECCs at 5 and 10 years of about $9 \% .{ }^{9,23}$

Finally, other studies have combined more than two surgical strategies (Intracorneal Rings segments, CXL and toric PIOL or simultaneous CXL and Photorefractive keratectomy and spherical PIOL), which highlights the potential need of several surgical strategies to achieve complete visual rehabilitation in these complex patients when contact lens fitting is not an option. ${ }^{24-26}$

\section{CONCLUSION}

Corneal cross-linking combined with PIOL implantation is a valid therapeutic approach for progressive keratoconus with moderate-to-high refractive errors, regular or mildly irregular astigmatism, and good CDVA, especially in the face of significant anisometropia. Corneal cross-linking is the only treatment available that has demonstrated the ability of stopping the progression of keratoconus. Phakic intraocular lenses s are effective and safe for the correction of moderate-to-high, regular refractive errors in both keratoconic and nonkeratoconic eyes. Stability of the disease should be confirmed before considering any refractive procedure.

\section{CLINICAL SIGNIFICANCE}

This review article summarizes the clinical outcomes of the combination of CXL and PIOL implantation as a 


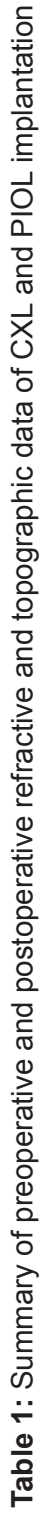

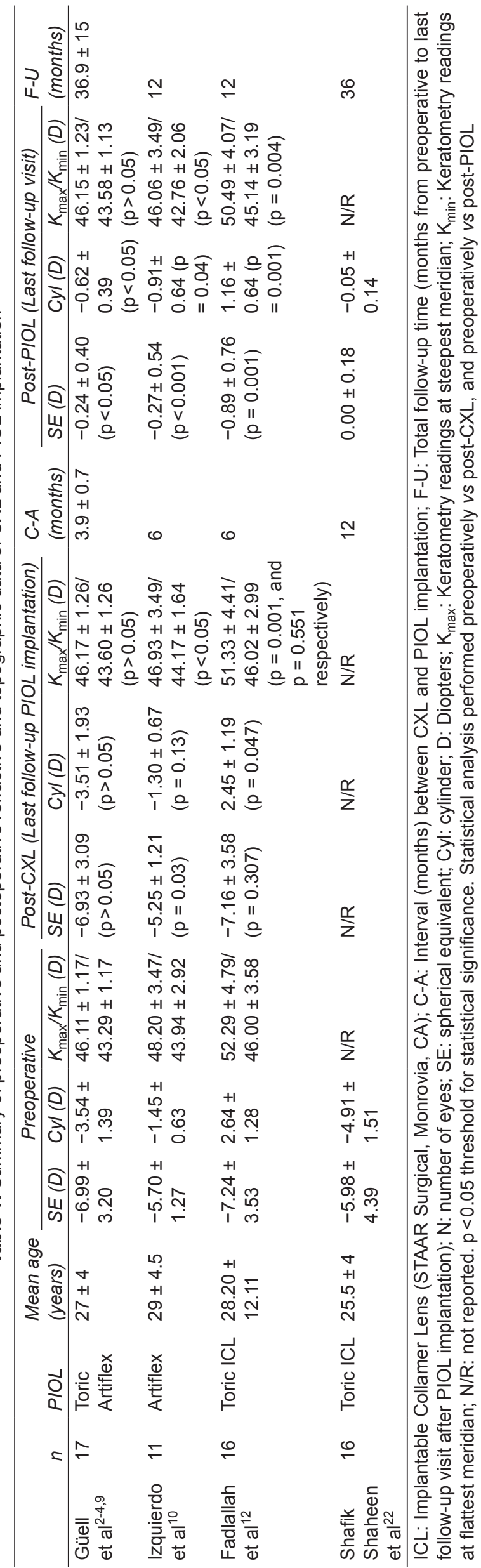

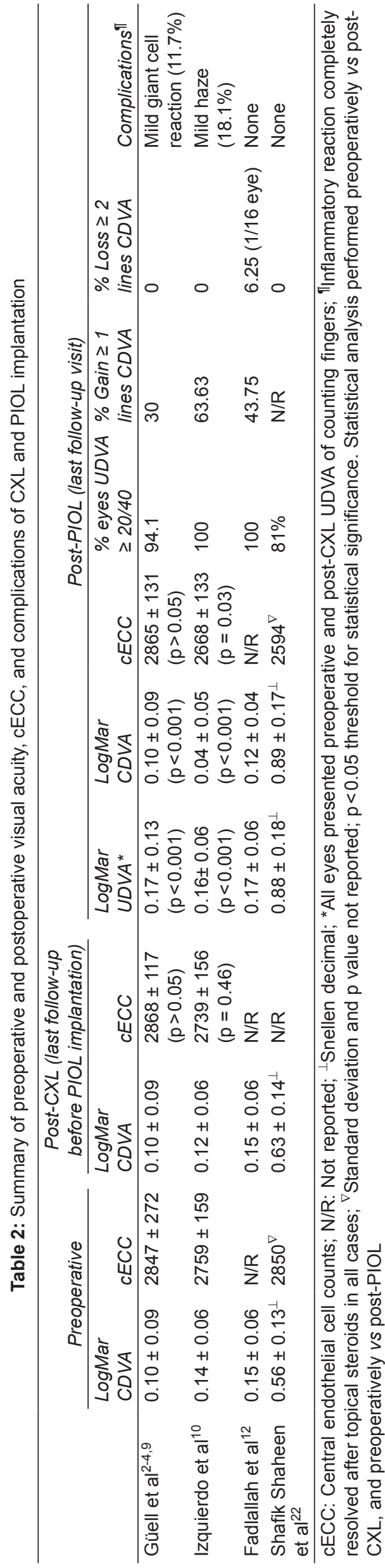


valid therapeutic approach for visual rehabilitation of progressive keratoconus. Although longer-term follow-up clinical data from prospective RCTs are needed, clinical outcomes are excellent and equivalent to nonkeratoconic eyes up to 3 years after surgery.

\section{REFERENCES}

1. Ferreira TB, Güell JL, Manero F. Combined intracorneal ring segments and iris-fixated phakic intraocular lens for keratoconus refractive and visual improvement. J Refract Surg 2014 May;30(5):336-341.

2. Güell JL, Morral M, Malecaze F, Gris O, Elies D, Manero F. Collagen crosslinking and toric iris-claw phakic intraocular lens for myopic astigmatism in progressive mild to moderate keratoconus. J Cataract Refract Surg 2012 Mar;38(3): 475-484.

3. Güell JL, Morral M, Salinas C, Elies D, Gris O, Manero F. Four-year follow-up of intrastromal corneal ring segments in patients with keratoconus. J Emmetropia 2010 Jan;1:9-15.

4. Güell JL, Morral M, Salinas C, Elies D, Gris O, Manero F. Intrastromal corneal ring segments to correct low myopia in eyes with irregular or abnormal topography including forme fruste keratoconus: 4-year follow-up. J Cataract Refract Surg 2010 Jul;36(7):1149-1155.

5. Gomes JA, Tan D, Rapuano CJ, Belin MW, Ambrósio R Jr, Guell JL, Malecaze F, Nishida K, Sangwan VS; Group of Panelists for the Global Delphi Panel of Keratoconus and Ectatic Diseases. Global consensus on keratoconus and ectatic diseases. Cornea 2015 Apr;34(4):359-369.

6. Hersh PS, Stulting RD, Muller D, Durrie DS, Rajpal RK; United States Crosslinking Study Group. United States multicenter clinical trial of corneal collagen crosslinking for keratoconus treatment. Ophthalmology 2017 Sep;124(9):1259-1270.

7. Lombardo M, Giannini D, Lombardo G, Serrao S. Randomized controlled trial comparing transepithelial corneal crosslinking using iontophoresis with the Dresden protocol in progressive keratoconus. Ophthalmology 2017 Jun;124(6): 804-812.

8. Choi M, Kim J, Kim EK, Seo KY, Kim TI. Comparison of the conventional dresden protocol and accelerated protocol with higher ultraviolet intensity in corneal collagen cross-linking for keratoconus. Cornea 2017 May;36(5):523-529.

9. Güell JL, Morral M, Gris O, Gaytan J, Sisquella M, Manero F. Five-year follow-up of 399 phakic Artisan-Verisyse implantation for myopia, hyperopia, and/or astigmatism. Ophthalmology 2008 Jun;115(6):1002-1012.

10. Izquierdo L Jr, Henriquez MA, McCarthy M. Artiflex phakic intraocular lens implantation after corneal collagen crosslinking in keratoconic eyes. J Refract Surg 2011 Jul;27(7): 482-487.

11. Kymionis GD, Grentzelos MA, Karavitaki AE, Zotta P, YooSH, Pallikaris IG. Combined corneal collagen cross-linking and posterior chamber toric implantable collamer lens implantation for keratoconus. Ophthalmic Surg Lasers Imaging 2011 Feb;17;42.
12. Fadlallah A, Dirani A, El Rami H, Cherfane G, Jarade E. Safety and visual outcome of Visian toric ICL implantation after corneal collagen cross-linking in keratoconus. J Refract Surg 2013 Feb;29(2):84-89.

13. Wollensak G. Crosslinking treatment of progressive keratoconus: new hope. Curr Opin Ophthalmol 2006 Aug;17(4): 356-360.

14. Grewal DS, Brar GS, Jain R, Sood V, Singla M, Grewal SP. Corneal collagen crosslinking using riboflavin and ultravioletA light for keratoconus: one-year analysis using Scheimpflug imaging. J Cataract Refract Surg 2009 Mar;35(3):425-432.

15. Kohnen T, Kook D, Morral M, Güell JL. Phakic intraocular lenses: part 2: results and complications. J Cataract Refract Surg 2010 Dec;36(12):2168-2194.

16. Alfonso JF, Fernández-Vega L, Lisa C, Fernandes P, GonzálezMéijome JM, Montés-Micó R. Collagen copolymer toric posterior chamber phakic intraocular lens in eyes with keratoconus. J Cataract Refract Surg 2010 Jun;36(6):906-916.

17. Kamiya K, Shimizu K, Ando W, Asato Y, Fujisawa T. Phakic toric Implantable Collamer Lens for the correction of high myopic astigmatism in eyes with keratoconus. J Refract Surg 2008 Oct;24(8):840-842.

18. Venter J. Artisan phakic intraocular lens in patients with keratoconus. J Refract Surg 2009 Sep;25(9):759-764.

19. Budo C, Bartels MC, van Rij G. Implantation of Artisan toric phakic intraocular lenses for the correction of astigmatism and spherical errors in patients with keratoconus. J Refract Surg 2005 May-Jun;21(3):218-222.

20. Gupta S. Implantable contact lenses in keratoconus. Int J Kerat Ect Cor Dis 2016 Jan-Apr;5(1):17-20.

21. Kymionis GD, Grentzelos MA, Portaliou DM, Kankariya VP, Randleman JB. Corneal collagen cross-linking (CXL) combined with refractive procedures for the treatment of corneal ectatic disorders: CXL plus. J Refract Surg 2014 Aug;30(8): 566-576.

22. ShafikShaheen M,El-Kateb M,El-Samadouny MA,ZaghloulH. Evaluation of a toric implantable collamer lens after corneal collagen crosslinking in treatment of early-stage keratoconus: 3-year follow-up. Cornea 2014 May;33(5):475-480.

23. Tahzib NG, Nuijts RM, Wu WY, Budo CJ. Long-term study of Artisan phakic intraocular lens implantation for the correction of moderate to high myopia: ten-year follow-up results. Ophthalmology 2007 Jun;114(6):1133-1142.

24. Dirani A, Fadlallah A, Khoueir Z, Antoun J, Cherfan G, Jarade E. Visian toric ICL implantation after intracorneal ring segments implantation and corneal collagen crosslinking in keratoconus. Eur J Ophthalmol 2014 May-Jun;24(3):338-344.

25. Coşkunseven E, Sharma DP, Jankov MR 2nd, Kymionis GD, Richoz O, Hafezi F. Collagen copolymer toric phakic intraocular lens for residual myopic astigmatism after intrastromal corneal ring segment implantation and corneal collagen crosslinking in a 3-stage procedure for keratoconus. J Cataract Refract Surg 2013 May;39(5):722-729.

26. Assaf A, Kotb A. Simultaneous corneal crosslinking and surface ablation combined with phakic intraocular lens implantation for managing keratoconus. Int Ophthalmol 2015 Jun;35(3):411-419. 